\title{
Motivational Personnel Management System of a Hotel Enterprise
}

\author{
Rimma Zaharova ${ }^{1^{*}}$ \\ ${ }^{1}$ Don State Technical University, 1 sq. Gagarina, Rostov-on-Don, 344000, Russia
}

\begin{abstract}
This article aims to examine the contribution of employees to achieving profitability and competitive advantage in the hospitality industry, the importance of motivation in improving employee performance, and the role of managers in motivating employees to improve their efficiency and commitment. Human needs include physiological component of a person, these needs are laid down from childhood at the genetic level. These include breathing, sleeping, eating. Secondary needs differ from primary ones in that they are developed during a person's life; they include such needs as recognition, respect, prosperity and fame. It is not possible to directly see individual needs of a person, they can be noticed only at certain intervals of observation of a person.
\end{abstract}

\section{Introduction}

There is a close relationship between motivation and stimulation. To develop the personal qualities of an employee of a hotel enterprise, such as responsibility, hard work, patience, perseverance and efficiency, external motivation should be exerted on the internal motivation, in other words, stimulation should influence the formation of motivation.

Such concepts as motive and incentive have different roots. The sources of origin of these concepts are also dissimilar; in exceptional cases, the stimulus can be transformed and take the form of a motive. The purpose for rewarding an employee's performance can be an incentive. An employee for his work in the hotel receives a reward or punishment, this proves that an incentive is not a reward.

The hospitality industry has long struggled to establish what really makes hotel employees motivated and satisfied with their jobs. It is believed that high employee turnover in the hospitality industry is due to the nature of the work, its low pay and long working hours. Thus, to effectively address this employee turnover problem, employee motivation can become an ongoing and critical issue for hotel operations managers.

Hotel staff value recognition, especially when they go beyond their daily duties to satisfy the guest. Staff motivation levels in a hotel often follow the lead of company executives who can delegate authority. When employees feel empowered to make decisions and have all the tools they need to do their jobs properly, they are more motivated and more likely to stick with their jobs longer than employees who don't feel like they have management support.

* Corresponding author: zrm60@yandex.ru 
The biggest problem with employee motivation in the hospitality industry is that employees often motivate themselves based on their perceptions of what they want to achieve and how they can achieve it. However, if managers know what their employees want from their jobs, they can create a work environment that matches their needs and wants. At the same time, well-informed managers can avoid common mistakes that tend to reduce employee motivation.

The amount of effort an employee makes to achieve the hotel's goals depends on whether he believes that these efforts will lead to the satisfaction of his own needs and desires. When the need or desire is not satisfied, the person tries to relieve tension. With this straightforward approach to employee motivation, the key to facilitating motivation lies in managers knowing exactly what their employees want out of their jobs.

If we consider human psychology, then we can come to the conclusion that a person's response to stimuli is not conscious and controllable, and the response of each person can be different and depends on his personality. Based on the above, we can conclude that these concepts are interdependent and have a connection with each other, the reaction of workers depends on motives and goals.

A variety of external and internal forces that are intertwined with the concept of motivation are pushing the hotel industry employee to make a decision and achieve the goals. For this, the employee will need both moral and physical strength, and his personal qualities will play an important role.

\section{Materials and methods}

Let's consider and understand in similar at first glance concepts like "motivating" and "motivation". Motivation describes the internal motivation of an employee to perform actions. Motivating is the procedure for forming the desire to perform actions. An employee to achieve specific goals for a given company can be motivated by the company itself [1].

Dwelling in more detail on the types of motivation, one can distinguish between both external and internal types of motivation. The stages of development of economic relations are closely related to the emergence and existence of the theories considered, which influenced the rethinking of the roles of motives and incentives in the labor activity of workers.

We can say that motivation for each person can be perceived differently [2].

The satisfaction of the employee's needs can be fulfilled in full, in part, or not at all.

To date, all existing theories are conventionally divided into three groups: initial [2]; meaningful [3]; procedural [4].

Meaningful theories of motivation include the scientific works of A. Maslow, K. Alderfer, D. McClelland, F. Herzberg. They assess the factors that affect staff motivation. Each author has tried to prioritize needs as the main driving force behind action.

The underlying theory is the work of Abraham Maslow. He created the famous pyramid of values based on 5 needs, dividing them into primary and secondary.

\section{Results}

Without satisfying basic needs, a person will not be able to exist and, therefore, fully develop. From the point of view of labor motivation, basic values are material incentives (due to which the existence of the individual is ensured). This means that when choosing a job, an employee will primarily focus on the first points of the schedule. In this case, the physiological needs will include receiving a stable wage (for the purchase of necessary 
goods and food) and other monetary rewards, as well as working conditions (sleep schedule, compliance with sanitary rules).

The need for security includes retirement and social security, which gives confidence in the future. This can be a guarantee of stability and reliability of work, social guarantees, life insurance, pension and health insurance.

Minor needs are social. In order to satisfy the group "the need for belonging to a social group", it is necessary to carry out a number of activities: Organization of collective events (celebration of significant holidays, field trips); creation of an internal corporate culture; joint participation in sports and other competitions; holding meetings and others.

The need for respect and recognition is usually present among the management of the company, for whom status is very important. Maslow divides this group into two parts. In the first part, self-affirmation is associated with the word "achievement". These are human aspirations that allow themselves and others to prove their strength, influence and sufficiency. The second part is related to "prestige". Motivation and personality are associated with valuable things that help ensure a good reputation and public credibility. The fifth step "the need for self-expression" is created for those who need something high. It is believed that the more developed the intellect, the more serious the needs at the top.

Despite the fact that the schedule is very structured, the system itself is unprofitable in advance (in practice, not realizable). Everyone in the world knows the famous "Maslow pyramid" and there are many attempts to use it in real life, but none have been successful. This is due to the fact that the next step has the right to satisfaction only when the previous one is completely satisfied. Due to the uniqueness and individuality of a person, there is a redistribution of values. So for some, the need for communication with the team may be more important than one's recognition.

$\mathrm{K}$. Alderfer is generally in agreement with Maslow's theory, but reserved the right to modernize it

The desire to gain recognition (the need for involvement) depends on building the process of work in an atmosphere of mutual assistance and community of interests.

Unlike Maslow's pyramid, this theory has no hierarchy and can have varying degrees of manifestation. I would like to note that this is one of the few theories that is used in real life. To diagnose an actualized need, empirical testing of the theory is used (based on TAT tests).

The following theory, created in the late 1950s by Frederick Herzberg, is associated with elucidating the grounds for satisfaction and dissatisfaction with a person's activities (Table 1).

Table 1. F. Herzberg's two-factor concept.

\begin{tabular}{|c|c|}
\hline Hygiene factors & Motivating factors \\
\hline Company policy and administration & Success, achievement \\
\hline Quality of supervisor control & Career \\
\hline Salary & Recognition \\
\hline Interpersonal communication & Job responsibility \\
\hline Status, work regimen & Promotion \\
\hline
\end{tabular}

The second group of "motivating factors" corresponds to the highest needs and is aimed at high results [7].

According to V. Vroom, motivation is viewed as a choice management process, that is, in his opinion, people are constantly in a state of motivation. As an example, he cites entering a university and obtaining a diploma for employment in a high-paying job in the future. 
He identifies 3 factors affecting motivation, presented in Fig. 1.

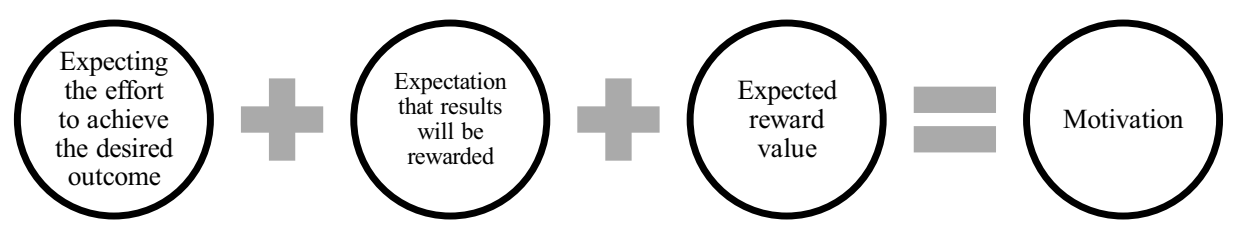

Fig 1. Vroom's theory of expectations.

D.S.Adams' theory of justice was proposed in 1963 (Fig. 2). In another way it is called the theory of "equality". The theory is based on the subjective ratio of effort expended and rewards received.

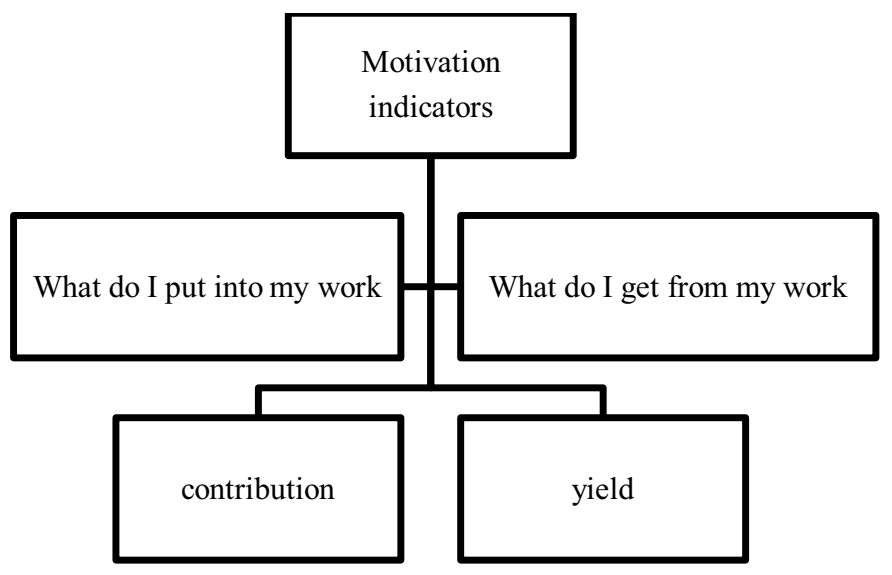

Fig 2. Adams' theory of equiality.

Moreover, people are constantly comparing rewards to those who have done similar work. If another employee has more remuneration, then there is discomfort and a feeling of injustice, which greatly affects the desire to continue working. Observing the imbalance, workers seek to reduce the amount of effort being applied [8].

Managers can avoid adverse outcomes by explaining to employees the reasons for the differences in remuneration.

The main function of modern management in the hotel industry is the formation of motivations [9].

Wages are the main stimulating effect of the employee's work, if the employee has a large salary, then the company's image is improved in the labor markets, which contributes to attracting highly qualified personnel.

The economic system of motivation for the hotel business is hidden within the driving force of the general economic model, which links and streamlines all targeted economic efforts and integrates them into a coherent whole. In this process, motivation manifests itself as the main driving force of creation.

Work motivation is a system of methods, procedures and actions that encourages, directs and enhances the behavior of certain employees in order to achieve greater and more favorable results. 
Often the monetary method has its drawbacks. For example, it is sometimes very difficult to evaluate the work done by an employee in a hotel. If the results of the employee's labor activity need to be honored, then in most cases difficulties arise.

There is also one important drawback of the monetary method, the essence of this drawback is that the employee is faced with more important phenomena than wages, various difficulties are manifested [10].

Additional payments, bonuses, allowances also refer to monetary methods, they are material rewards for work activities that are beneficial. They include the initiative of the employee, for experience, rationalization proposals for the company.

In a situation where the main part of the employee's income will be calculated only in bonuses, the employee will not have a sense of stable wages, which will be necessary to meet his personal needs, despite how high his level of bonuses will be, such an employee will quit. This requires a properly developed motivation system, because it is the basis of all programs.

It is the material part that lures workers into the hotel industry. Before getting a job, a person starts from the level of wages offered by this or that company.

If an employee is financially secure, then his efficiency and productivity will depend on intangible methods.

Economic incentives for personnel in hospitality companies are based on these basic principles (Fig. 3):

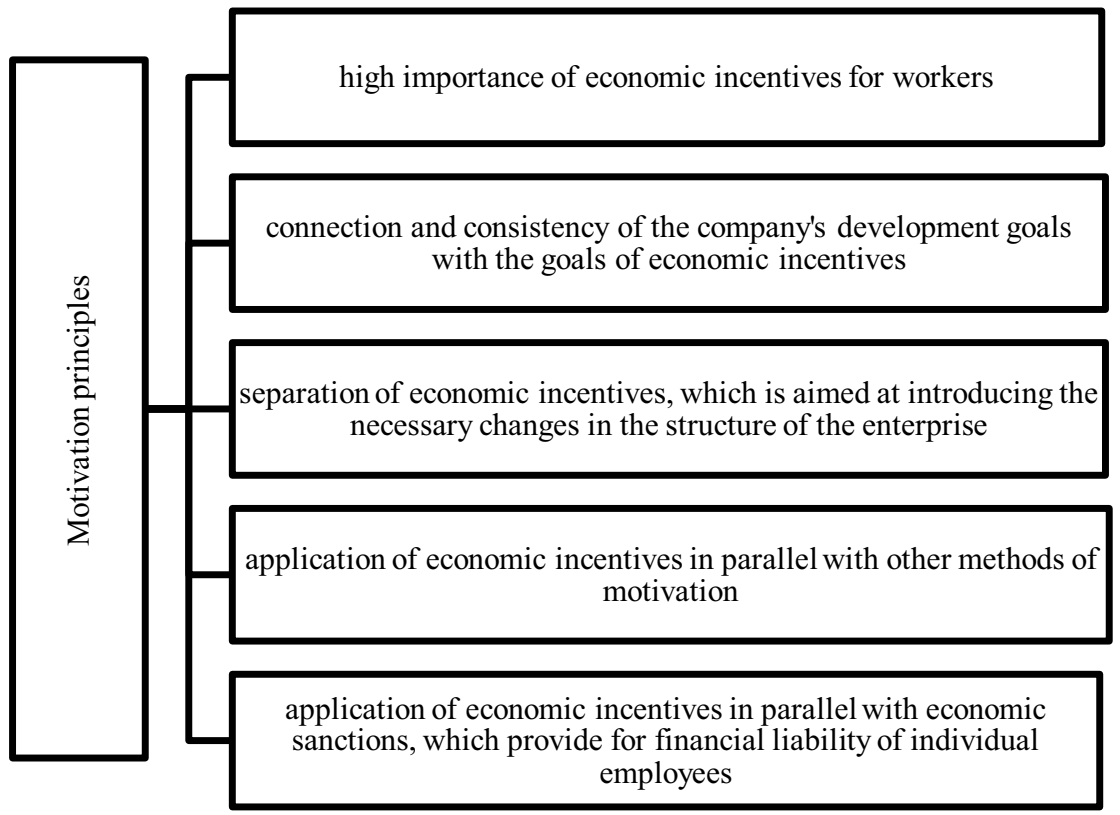

Fig. 3. Principles of economic incentives for hotel personnel.

Let us consider non-monetary forms of incentives and labor motivation (non-material) [11].

Personnel management specialists use various non-material methods of motivation and incentives, depending on the goals and objectives of the enterprise and its strategies [12].

As an example, we can cite a number of enterprises in the hotel industry, where the construction of personnel policy consists of holding sports events between the branches of the organization. An interesting fact is that when hiring, managers gave preference to those 
applicants who achieved good heights in their sports career, despite the fact that professional qualities remained, as it were, in the shadows.

For the active work of an employee in a hotel company, his interests are influenced, thereby increasing his efficiency. If we take into account a separate group, team or employee, then the incentives act as an external driving force in the work, the functioning of the enterprise. The construction of an incentive system at an enterprise in the hotel industry is determined by the professionalism of managers, its capabilities and goals. In order to achieve an increase in activity, stimulation on the working factors of the external environment a process takes place that regulates its impact. Motivation stimulates internal activity, and stimulation flows through the possibilities of external needs.

\section{Discussion}

Hotel personnel management is a rather complex system that is aimed at maintaining vertical and horizontal communications and constantly optimizing work. This system should ensure the efficiency of the work of all employees, and this can only be achieved when each employee is in his place. At first glance, the implementation of such a principle seems simple, but, nevertheless, this task is not so simple, since it is necessary to combine the interests of the enterprise with the goals and interests of the personnel. The main steps for the development of personnel management allow combining possible and necessary factors. Let us consider these stages in more detail [13-18].

The first stage: planning the needs of the enterprise in personnel. Personnel planning can be divided into strategic and ongoing. Strategic planning is used at the first stages of the formation of an enterprise and its further development, especially when the strategy of the enterprise changes.

Undoubtedly, the consequences of the preference in personnel were reflected in labor productivity in those branches, because important tasks were solved by the wrong personnel that was needed. Motivational changes are achieved through technological actions and management decisions in the main segments of the hotel enterprise (Fig. 4):

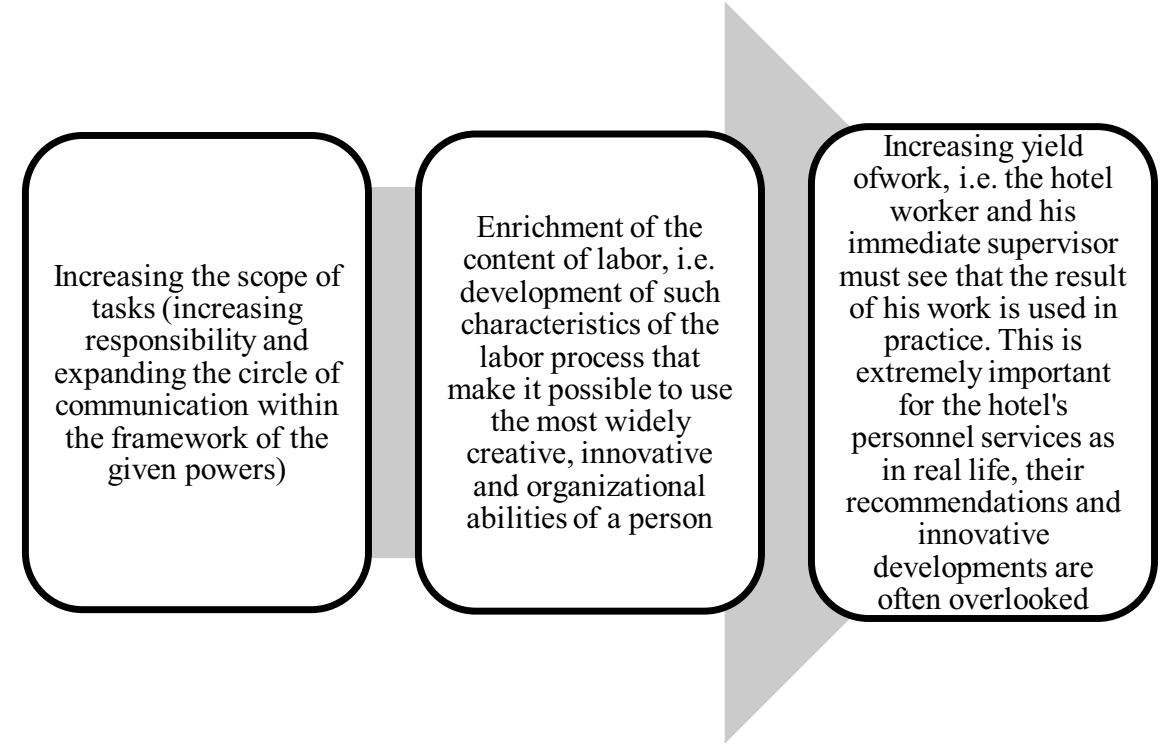

Fig. 4. Technological actions and management decisions in the main segments of the hotel enterprise. 
Ongoing planning should be used constantly under the conditions of stable operation of the enterprise. Staff planning in a hotel begins with a feasibility study for each position. Each position corresponds to a certain competence, which includes: certain qualifications and official powers.

The required number of personnel is indicated in the plans, based on standards and regulations, at similar enterprises or on the ability of an employee to perform this work in a certain unit of time [19].

Stage two: Functional recruitment is an ongoing process. The staff can be attracted from outside, or it can be redistributed within the enterprise. It is possible to attract specialists from the outside with the help of advertisements, competitions, in universities, etc. At the same time, each employee, hiring for a new job, hopes that he will be able to realize his full potential and for this all conditions will be created at the enterprise.

Stage three: managing employee behavior. Although this stage is the third, nevertheless, work with personnel is an ongoing process. The process starts from the moment the main staff is recruited and ends at the closure of the enterprise.

The fourth stage: to form the standards of personnel management. All this will help to legally maintain a balance between the goals of the manager and the employee. If the subjects of production comply with the norms and rules adapted for the given enterprise, then this can serve as a guarantee of minimizing conflicts. A good system will be able to ensure the timely and painless inclusion of a new employee in production and the team.

The fifth stage: to ensure the process of realizing the potential of the personnel. In order to create an effective team, it is necessary to form transparent material and non-material labor incentives. Employees, working at the enterprise, receive wages. Salary levels are considered to be a very good incentive for effective work. In addition, a person can have fun, realizing that he is important and valuable to the enterprise. Therefore, if you encourage the employee morally, then this can also serve as a significant motive. And a combination of tangible and intangible incentives can create an effective work environment.

The sixth stage: updating the personnel work of the hotel. To implement this function, it is necessary to constantly improve the personnel management system, using the advanced training of specialists [19]. The main function of such a service is to stimulate the acquisition of education - from courses to the second higher education. In addition, employees must master related professions, learn to work with new equipment and master new technologies.

Also, the most important mechanism for the implementation of the motivational system in the hotel is teamwork. Teamwork enhances the creativity of hotel workers when well managed by an open and innovative leader. This allows one to overcome obstacles faster and more efficiently while harmony reigns in the group, because if the opposite cannot happen, it helps to visualize problems and achieve goals in a shorter time, when the distribution of tasks is clearly ordered and defined either on a common disk or in other management tools. Teamwork helps each hotel employee to progress and grow, because if everyone works with a good leader, simultaneous growth is possible, problems are solved faster. This creates a shared identity, although people need to be classified as more and more teams tend to perceive themselves not only as a cohesive group, but also as many small subgroups..

Teamwork provides moral support at critical moments such as month-end reports, routine tasks, etc. If there is group cohesion, there is always support or leverage to turn to for a motivational proposal. This technique can lead to the development and improvement of innovations.

Having a highly motivated hotel team is what matters in the hospitality industry. Today, when there is a lot of competition, it is necessary to act in a unique way, and a good 
strategy to stand out, and such a strategy is to manage the motivational abilities of the team. This ability to manage teams can ensure that hotel employees never want to leave.

Thus, a motivated employee demonstrates behaviors and activities that are highly beneficial to the hotel. However, the hotel's success is not limited to its financial results. It must find new ways to attract and retain its employees.

\section{Results}

As a result, we note that the efficiency of an employee of a hotel enterprise is based on his motivation, since the last few decades have been characterized by a radical change in management's understanding of the importance of the workforce in achieving strategic hotel goals. Management experts agree that in situations where competitors have similar financial resources and organizational infrastructure, competitive advantage can only be achieved through well-trained and highly motivated employees.

With the exponential expansion of the hospitality industry, capacity building in business and tourism centers, huge competition has arisen across all sectors of the hospitality industry. Service-oriented by nature, hotels work towards achieving quality service and enhancing customer satisfaction in order to achieve a competitive advantage.

Thus, employee motivation is seen as the most important task of hotel management. Therefore, the main task of the manager is to clarify the key motivation and combine it with the tasks and goals that his hotel needs. As a result, the hotel gets a satisfied employee who clearly understands his potential, who works hard to increase his salary, but globally - for the company's profit.

\section{References}

1. T.Y. Bazarov, T.Yu. Personnel management (experience of sociological research) (INFRA-M, Moscow, 2019)

2. M. Dubovin, Personnel Management, 3, 40-48 (2018)

3. P.V. Zhuravlev, P.V. World experience in personnel management. Review of foreign sources (UNITI, Moscow, 2017)

4. A.A. Kozlov, Management in Russia and Abroad, 1, 25-30 (2018)

5. A.A. Kozlov, Management in Russia and Abroad, 2, 28-36 (2018)

6. P. Doyle, Management: Strategy and Tactics (Piter Publishing House, St. Petersburg, 2019)

7. O.N. Volgina, Personnel labor motivation ( Examination, Moscow, 2020)

8. G.Y. Goldstein, Strategic management: textbook (TRTU Publishing House, Taganrog, 2021)

9. E.V. Maslov, Enterprise personnel management: textbook (INFRA-M, Moscow, 2018)

10. A.V. Busygin, Effective management: textbook for universities (INFRA-M, Moscow, 2019)

11. A.K. Sahakyan, Personnel management in the organization: Personnel policy, motivation, structure (Peter, SPb, 2019)

12. S.I. Samygin, Fundamentals of personnel management: textbook (PHOENIX, Rostovon-Don, 2017) 
13. L.N. Kazmina, V.S. Makarenko, V.V. Provotorina, T.N. Grigorenko, International Journal of Economics and Business Administration, 7, 510-520 (2019), doi: $10.35808 / \mathrm{ijeba} / 297$

14. L.N. Kazmina, V.V. Provotorina, Humanities and Socio-Economic Sciences, 5(96), 109-114 (2017)

15. V.V. Provotorina, L.N. Kazmina, A.S. Petrenko, G.E. Ekinil, E3S Web of Conferences 175, 10002 (2020), doi: 10.1051/e3sconf/202017510002

16. L.N. Kazmina, V.S. Makarenko, V.V., Provotorina, E.M. Shevchenko, E3S Web of Conferences, 175, 10001 (2020), doi:10.1051/e3sconf/202017510001

17. V.V. Provotorina, L.N. Kazmina, A.S. Petrenko, V.S., Makarenko, Lecture Notes in Civil Engineering, 130, 20-32 (2020), https://doi.org/10.1007/978-981-33-6208-6_3

18. P.F. Drucker, An effective leader. Publisher (Mann, Ivanov and Ferber, 2019)

19. A.G. Maklakov, Professional psychological selection of personnel. Theory and practice (Peter, SPb, 2018) 